\title{
GREENHOUSE GASES AND GLOBAL WARMING
}

\section{Timothy J. Wallington}

Ford Motor Company, Dearborn, Michigan, USA

\section{Jayaraman Srinivasan}

Centre for Atmospheric and Oceanic Sciences, Indian Institute of Science, Bangalore, India

\section{Ole John Nielsen}

Department of Chemistry, University of Copenhagen, Copenhagen, Denmark

\section{Ellie J. Highwood}

Department of Meteorology, University of Reading, Reading, U.K.

Keywords: Global warming, greenhouse effect, greenhouse gas, climate models, climate change, chlorofluorocarbons, nitrous oxide, carbon dioxide, ozone, radiative forcing, global warming potential, solar radiation, solar constant, atmospheric lifetime

\section{Contents}

1. Introduction

2. Greenhouse Effect

3. Greenhouse Gases

3.1. Carbon Dioxide $\left(\mathrm{CO}_{2}\right)$

3.2. Methane $\left(\mathrm{CH}_{4}\right)$

3.3. Nitrous Oxide $\left(\mathrm{N}_{2} \mathrm{O}\right)$

3.4. Halogenated Organic Compounds

3.5. Sulfur Hexafluoride $\left(\mathrm{SF}_{6}\right)$

3.6. Ozone $\left(\mathrm{O}_{3}\right)$

4. Radiative Forcing of Climate Change

5. Non Greenhouse Gas Radiative Forcing

5.1. Aerosols

5.2. Land Use Changes

5.3. Solar Variability

5.4. Volcanic Activity

6. Climate Models

7. Predictions of Future Climate

8. Conclusions

Glossary

Bibliography

Biographical Sketches

\section{Summary}

Global warming is an important environmental issue which is rapidly becoming a part of popular culture. This paper provides an account of the science associated with this important issue. Historical evidence for past climate change is discussed. The difference between weather and climate is highlighted. The physics of the greenhouse effect and 
the concept of greenhouse gases are presented. The concepts of radiative forcing of climate change and global warming potential as measures of the absolute and relative strengths of greenhouse gases are discussed. Global warming, the enhancement of the natural greenhouse effect caused by emissions associated with human activities of greenhouse gases such as carbon dioxide, methane, nitrous oxide, and halogenated compounds (e.g. CFCs and $\mathrm{SF}_{6}$ ), is described. Techniques used to model past, current, and future climate are discussed. The models are based upon fundamental well established scientific principals and incorporate the current understanding of the complex feedback and couplings between the atmosphere, hydrosphere, and biosphere. Projections of future global climate change from state-of-the-art computer models are given. With our current level of scientific understanding we expect that over the next century the world will warm substantially.

\section{Introduction}

Weather and climate have a profound impact on living organisms on the planet. Ecological systems have evolved over geological time scales to suit the prevailing climate. The past 10 to 20 years have brought disturbing evidence that human activities may cause significant changes in future global climate. "Global Warming" is now an issue known to hundreds of millions of people across the world. We provide herein an overview of the current state of knowledge concerning greenhouse gases and global warming. For detailed scientific reviews of the subject with numerous references to the latest technical articles the reader should consult the comprehensive IPCC reports on the subject listed in the Bibliography. For a thought provoking historical perspective we recommend the reader consult the articles on the greenhouse effect published by Fourier in 1827 and Arrhenius in 1896. Our purpose here is to address the following questions: "Is global climate changing?", "To what degree are human activities responsible for climate change?", "What is the state of the science?", "What will future global climate be like?" and "What should we do?".

At this point it is germane to note the difference between weather and climate. Weather is the state of the atmosphere (temperature, humidity, precipitation, wind, cloud cover, etc.) in a particular location at a particular time; it fluctuates greatly and is notoriously difficult to predict. Climate is the time-averaged weather in a given geographical region. Climate is a temporal and spatial average and is consequentially much more predictable than weather. Thus, the average temperature during a given month in a particular area (climate) can be predicted with some confidence, however, the temperature at a given time and location (weather) is much more difficult to predict. Climate varies from month to month, season to season, and year to year. Statistically significant changes in climate occurring over a time scale of decades or longer constitute "climate change".

Climate change is not a new phenomenon in the Earth's history. The geological record shows that when viewed over a time scale of thousands of years the climate is in a state of more or less continual change with major ice ages occurring approximately every 100000 years. Regular occurrence of ice ages has an astronomical origin associated with subtle changes in the separation and relative orientation of the Earth and the Sun. Three regular variations occur as the Earth orbits around the Sun. First, the Earth's orbit is slightly elliptical and the eccentricity (degree to which it differs from circular) varies 
with a period of approximately 100000 years. Second, the Earth's rotational axis is tilted with respect to its orbital axis, the tilt oscillates between $21.6^{\circ}$ and $24.5^{\circ}$ with a period of approximately 41000 years (currently the tilt is $23.5^{\circ}$ ). Third, the month when the Earth is at perihelion (closest approach) with respect to the Sun changes with a period of approximately 23000 years. The three regular variations give rise to latitudinal and seasonal variations of solar radiation intensity (up to $10 \%$ variation in polar regions in summer time) which provides an astronomical forcing of climate leading to ice ages in which the global average temperature is believed to be approximately $5-10{ }^{\circ} \mathrm{C}$ cooler than at present. Currently, we are in a period between two ice ages, in the absence of other influences we will enter another ice age over a time scale of thousands of years. The rate of global temperature change associated with astronomical forcing is believed to be of the order of a few tenths of a degree Celsius per thousand years.

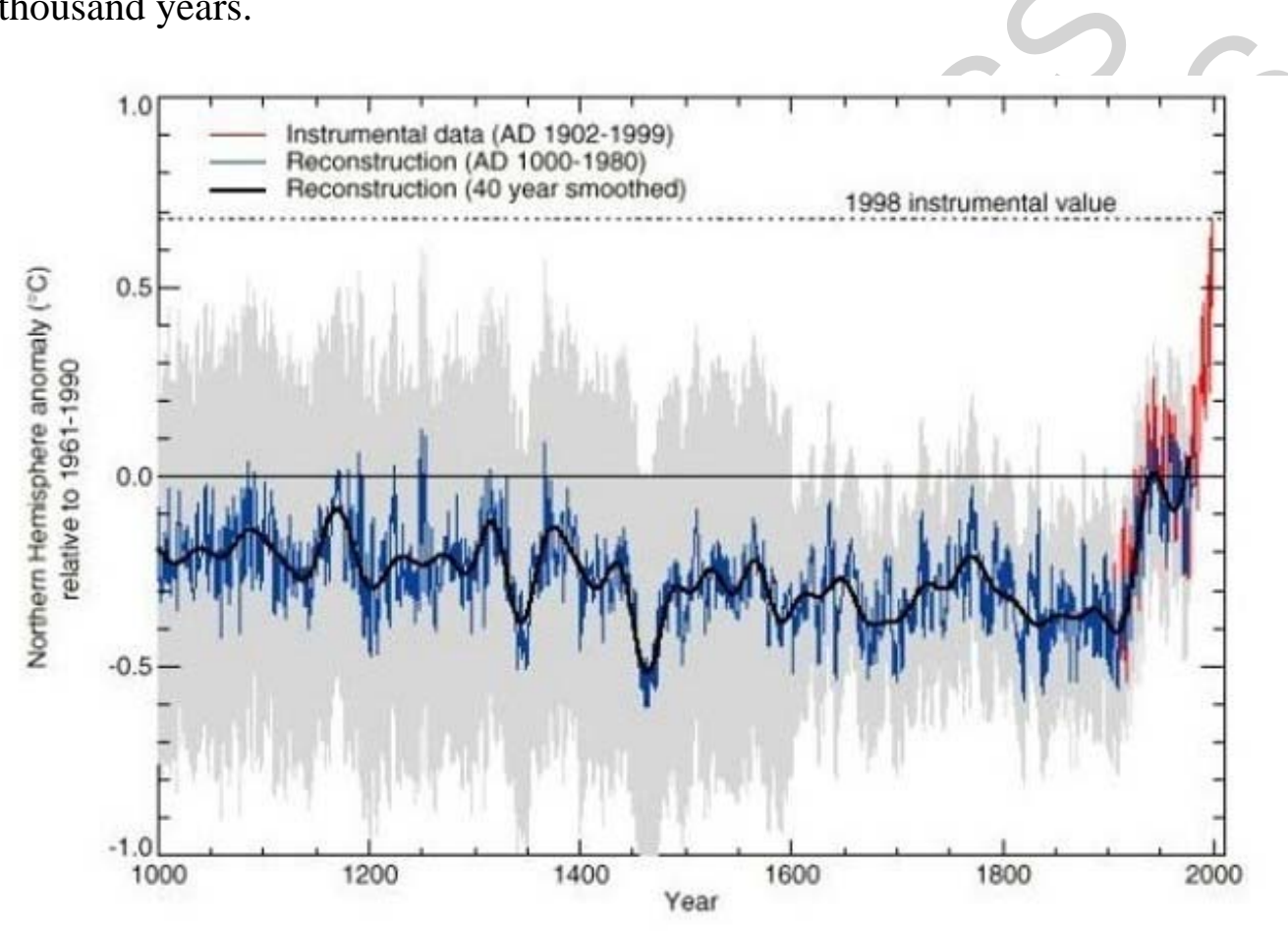

Figure 1. Average Northern Hemisphere temperature over the past 1000 years. Red $=$ instrumental record, blue $=$ reconstructed using proxy indicators, black $=40$ year average, grey = estimated uncertainty range. (Reproduced with permission from IPCC) 


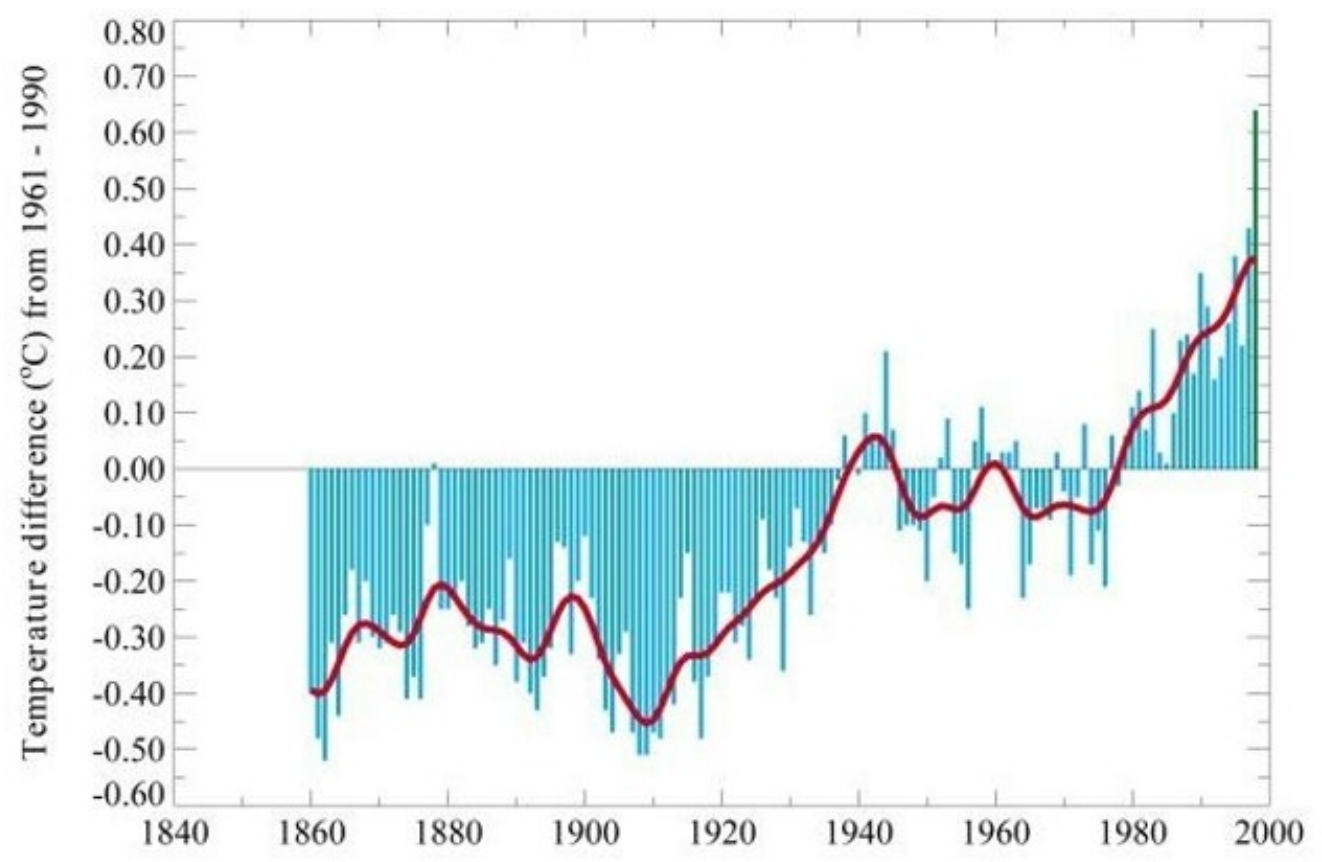

Figure 2. Global average temperature since 1860 (reproduced with permission from IPCC)

Figures 1 and 2 show the average annual Northern Hemisphere surface temperature over the past 1000 years and the average global temperature over the past 140 years. The red line in Figure 1 is the instrumental record which stretches back approximately 140 years, the blue line is the "reconstructed" temperature deduced from tree rings, ice cores, corals, and historical records. The black curve is the 40 year smoothed average. The temperature record for the Southern Hemisphere is less complete, but is consistent with, that of the Northern Hemisphere. Several interesting points arise from inspection of Figure 1. First, the average Northern hemispheric temperature is far from constant over the past 1000 years. Many fluctuations are observed. Second, there is a small but discernable general trend of decreasing temperature over the time period 1000-1900 with a magnitude consistent with that expected from astronomical forcing. Third, and most significant for the present discussion, there is a pronounced and abrupt (in geological terms) warming over the past century. Figure 2 provides a more detailed picture over the past 140 years which shows that the warming occurred during two periods (1910-1940 and 1980-present). The vertical bars in Figures 1 and 2 represent the difference between the average annual temperature for each year and the average for 1961-1990. 1998 was the warmest year, the 1990s was the warmest decade, and the 1900s was the warmest century in the past millennium. The data in Figures 1 and 2 indicate that global climate is changing.

The temperature record is not the only indication of a changing climate. There are many other indicators such as the substantial retreat of mountain glaciers in many locations around the world, decreased snow cover in the Northern hemisphere, decreased tropical precipitation, increased mid-to-high latitude precipitation, sea level rise, decreased extent of Arctic ice, and thinning of Arctic ice. The combined data prove beyond a reasonable doubt that global climate is changing. 
Having concluded that global warming is indeed occurring, the next question is "Should we be concerned?" The warming observed thus far $\left(0.6 \pm 0.2{ }^{\circ} \mathrm{C}\right.$ since the late nineteenth century) is modest and, in itself is unlikely to lead to a substantial global impact. Concern regarding global warming centers on the future climate. As discussed in detail below, it seems likely that most of the warming observed to date is associated with human activities releasing greenhouse gases such as carbon dioxide. In light of the long atmospheric lifetime of carbon dioxide, substantial increases in its emission during the past century, and expected increases in future emissions, the atmospheric concentration of carbon dioxide in the year 2100 will almost certainly be substantially greater than that today and the climate will continue to warm. The IPCC has considered numerous emission scenarios and concluded that global temperature may rise between 1.4 and $5.8{ }^{\circ} \mathrm{C}$ by 2100 (depending on emission scenario). It is instructive to consider Figure 1 and extrapolate a $1.4-5.8^{\circ} \mathrm{C}$ increase by 2100 , it is clear that when compared to natural variability over the past 1000 years an additional $1.4-5.8{ }^{\circ} \mathrm{C}$ change in the next 100 years would be very significant.

\section{Greenhouse Effect}

The history of the scientific understanding of the greenhouse effect can be traced back to Jean Baptiste-Joseph de Fourier in 1827. Fourier suggested that the atmosphere allows short wavelength radiation from the Sun to reach and warm the Earth's surface but blocks emission of longer wavelength radiation which would cool the Earth. Fourier compared this effect to that of the glass in a greenhouse (hence "greenhouse effect") and predicted that climate could be influenced by human activities. It is now known that prevention of the loss of warm air via convection is the main factor by which heat is retained in a greenhouse. However, for historical reasons, the terms "greenhouse effect" and "greenhouse gases" are still used when describing radiative trapping of heat in the atmosphere. In 1859 John Tyndall measured the infra-red (heat) trapping ability of water vapor, carbon dioxide, and methane and suggested that ice ages were caused by variations of the atmospheric levels of these gases. In 1896 Svante Arrhenius noted the release of large amounts of carbon dioxide by the burning of fossil fuel and estimated that a doubling of atmospheric carbon dioxide would warm the Earth by 5-6 ${ }^{\circ} \mathrm{C}$ (current climate models predict a $1.5-4.5{ }^{\circ} \mathrm{C}$ rise from doubling of carbon dioxide). In 1957 Roger Revelle and Hans Suess pointed out that the build-up of carbon dioxide in the atmosphere constituted a large scale geophysical experiment whose consequences were unknown. The following year (1958) was designated as the International Geophysical Year and saw the start of an ongoing program of continuous measurements of atmospheric carbon dioxide levels at Mauna Loa, Hawaii, by Charles Keeling which have showed that the levels of carbon dioxide are rising steadily (from 315 ppm in 1958 to $370 \mathrm{ppm}$ in 2001).

It has been known for over a hundred years that water vapor, carbon dioxide, and methane naturally present in the atmosphere trap heat in the atmosphere. It is relatively straightforward to estimate the magnitude of this "natural greenhouse effect". Sunlight arriving at the top of the atmosphere has a power of $1370 \mathrm{~W} \mathrm{~m}^{-2}$ (Solar Constant). The Earth presents a disc of area $\pi r^{2}$ ( $r$ = radius of Earth) towards the Sun and as the Earth rotates the sunlight is distributed over a surface area of $4 \pi \mathrm{r}^{2}$. Hence, the 24 hour average sunlight at the top of the atmosphere has a power of $1370 / 4=342 \mathrm{~W} \mathrm{~m}^{-2}$. Scattering by 
air molecules and reflection from surfaces (e.g. by clouds and snow) return an average of $107 \mathrm{~W} \mathrm{~m}^{-2}$ back to space leaving $235 \mathrm{~W} \mathrm{~m}^{-2}$ to heat the Earth. The only mechanism by which the Earth can cool itself is via emission of infrared radiation into space. At infrared frequencies the Earth behaves like a black body (when seen in IR light even "white" clouds and snow appear "black"). Emission from a black body is given by $\sigma \times$ $\mathrm{T}^{4}$, where $\sigma$ is the Stefan-Boltzmann constant $\left(5.67 \times 10^{-8} \mathrm{~J} \mathrm{~m}^{-2} \mathrm{~K}^{-4} \mathrm{~s}^{-1}\right)$ and $\mathrm{T}$ is the temperature of the black body. Hence, at radiative equilibrium we would expect the average surface temperature to be approximately $254 \mathrm{~K}\left(-19{ }^{\circ} \mathrm{C}\right)$. In reality the average surface temperature of the Earth is $288 \mathrm{~K}\left(15^{\circ} \mathrm{C}\right)$; the $34{ }^{\circ} \mathrm{C}$ difference is attributable to trapping of infrared radiation (heat) in the atmosphere by greenhouse gases, i.e. the natural greenhouse effect. Without the natural greenhouse effect the planet would be permanently frozen and devoid of life. "Global warming" refers to the enhanced greenhouse effect expected to result from an increase in atmospheric concentration of greenhouse gases resulting from emissions associated with human activities.

Absorption of infrared irradiation by greenhouse gases in the atmosphere has been well documented by satellite observations. Figure 3 shows the infrared radiation observed by a satellite looking down on the Sahara Desert. The dotted lines show emission spectra expected from blackbodies at various temperatures. The atmosphere is transparent at wavelengths of $10-12 \mu \mathrm{m}\left(800-1000 \mathrm{~cm}^{-1}\right)$, infrared radiation at this wavelength reaching the satellite comes directly from the surface of sand grains in the Sahara which have a temperature of $320 \mathrm{~K}\left(47^{\circ} \mathrm{C}\right)$. The $10-12 \mu \mathrm{m}$ region is known as the atmospheric window region. It can be seen from Figure 3 that the infrared radiation on either side of the atmospheric window is characteristic of emission from a blackbody which is significantly cooler than $320 \mathrm{~K}$. Thus, for example the intensity of radiation at wavelengths around $15 \mu \mathrm{m}$ is characteristic of that expected from a blackbody at approximately $220 \mathrm{~K}$. The apparent discrepancy between the temperature inferred from the $10-12 \mu \mathrm{m}$ and $15 \mu \mathrm{m}$ radiation is explained by the fact that carbon dioxide absorbs strongly at $15 \mu \mathrm{m}$. Hence, at $15 \mu \mathrm{m}$ the satellite does not observe emission from the Earth's surface but instead observes emission from high in the atmosphere where the temperatures are much colder than at the surface and the emission much weaker. Water vapor, ozone, and methane are also strong absorbers of infrared radiation. As indicated in Figure 3, the presence of these greenhouse gases in the atmosphere prevents the direct escape of terrestrial infrared radiation into space. Increases in the atmospheric concentrations of greenhouse gases such as carbon dioxide, water vapor, methane, and ozone will act to further hinder the escape of terrestrial infrared radiation and hence warm the Earth's surface. Certain industrial gases such as sulfur hexafluoride $\left(\mathrm{SF}_{6}\right)$ and the chlorofluorocarbons (CFCs) are powerful absorbers in the atmospheric window region and have a particularly pronounced greenhouse effect (on a mass basis $\mathrm{SF}_{6}$ is 22200 times more powerful a greenhouse gas than carbon dioxide). To understand the potential for human induced global warming we need to consider the human contribution to greenhouse gas levels. 


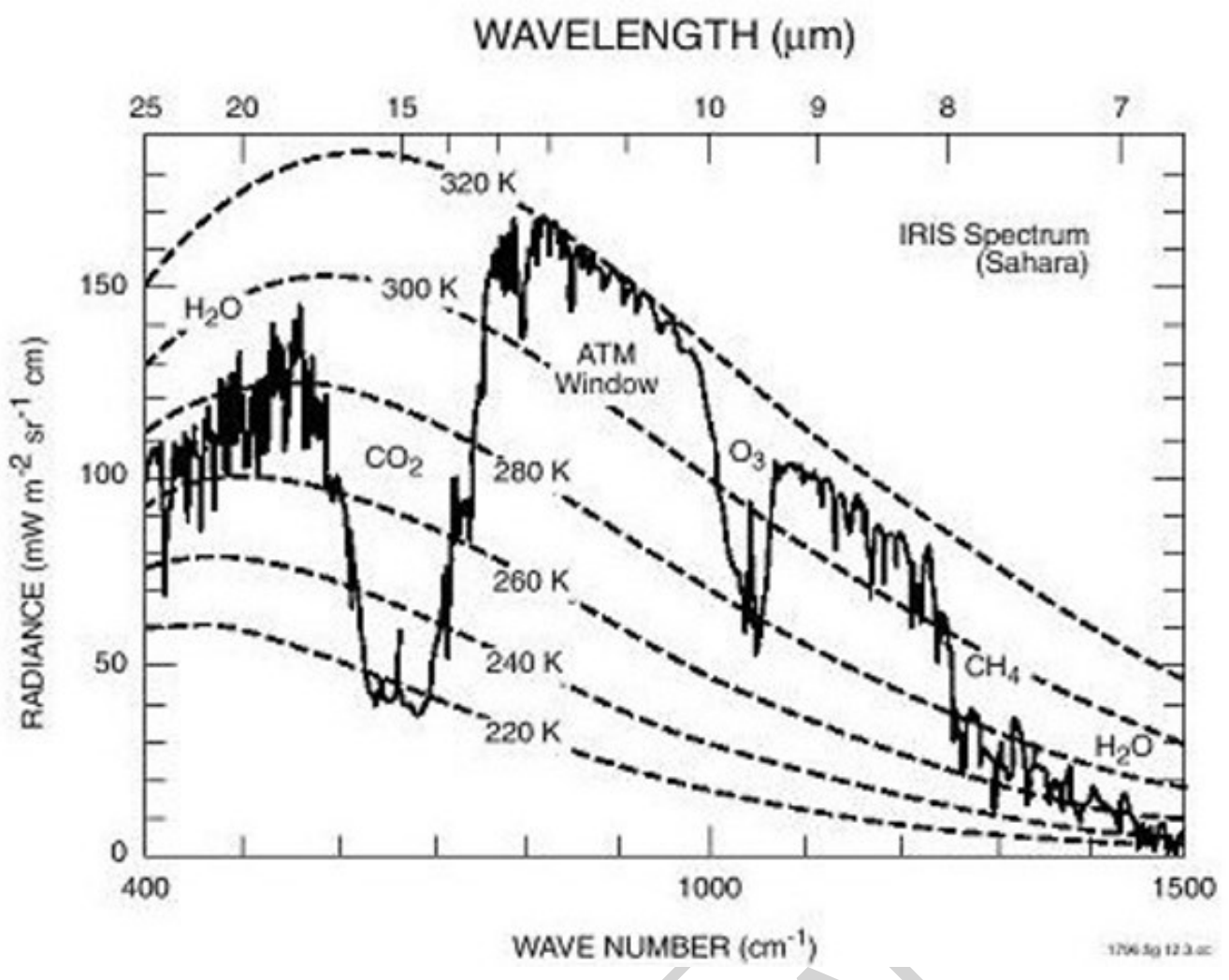

Figure 3. Terrestrial infrared radiation spectrum recorded by an orbiting satellite over the Sahara desert. (Reproduced with permission from Oxford University Press)

\section{TO ACCESS ALL THE 28 PAGES OF THIS CHAPTER, Visit: http://www.eolss.net/Eolss-sampleAllChapter.aspx}

\section{Bibliography}

Arrhenius, S., (1896). On the influence of carbonic acid in the air on the temperature of the ground, Phil. Mag., S. 41, 237-277. [First assessment of the likely climatic impact of doubling atmospheric $\mathrm{CO}_{2}$ levels due to fossil fuel combustion]

Fourier, J., (1827). Memoire sur les Temperatures du Globe Terrestre et des Escapes Planetaires, Mem. Aca. Sci. Inst. Fr., 7, 569-604. [First account of the greenhouse effect]

Houghton, J., (1997). Global Warming: The Complete Briefing, Cambridge University Press (1997). [Overview of global warming and its impacts]

http://www.epa.gov/globalwarming// [United States Environmental Protection Agency site with information on climate change and its impacts] 
http://www.giss.nasa.gov/ [National Aeronautics and Space Administration site with a wealth of global warming datasets and images.

http:/www.ipcc.ch/ [Home page for Intergovernmental Panel on Climate Change]

http://www.met-office.gov.uk/research/hadleycenter/ [General information about climate modeling and results (including animated movies) from climate models at Hadley Center]

http://www.pewclimate.org/ [Non governmental organization site for global warming information]

Intergovernmental Panel on Climate Change, (1996). Climate Change 1995: The Science of Climate Change, Cambridge University Press (1996). [Comprehensive account of the state of scientific understanding of climate change as of 1996 with numerous references]

Intergovernmental Panel on Climate Change, (2001). Climate Change 2001: The Scientific Basis, Cambridge University Press. [Comprehensive account of the current state of scientific understanding of climate change with numerous references]

\section{Biographical Sketches}

Timothy J. Wallington was born in England in 1958. He received his B.A. in Natural Sciences $\left(1^{\text {st }}\right.$ Class) in 1981 and his Ph.D. in Physical Chemistry in 1983 from Oxford University under the supervision of Richard Wayne. In 1984 he moved to the Statewide Air Pollution Research Center in Riverside, California, to work with James N. Pitts, Jr. and Roger Atkinson. In 1986 he moved to the National Bureau of Standards (now National Institute of Standards and Technology) near Washington D.C. to work with Michael Kurylo. From 1987 he has worked in the Scientific Research Laboratories of Ford Motor Company in Dearborn to establish the environmental impact of vehicle emissions. In 1998 he spent a year as a Humboldt Research Fellow in Wuppertal, Germany with Karl Heinz Becker. He has co-authored over 300 scientific articles and 2 books in the area of atmospheric science.

Jayaraman Srinivasan was born in India in 1947. He received his B.Tech. in Mechanical Engineering in 1969 from Indian Institute of Technology, Madras, India, his M.S. in Mechanics in 1971 from State University of New York, Stony Brook and his Ph.D. in Mechanical Engineering in 1975 from Stanford University. From 1975 to 1982 he was a faculty member in the Department of Mechanical Engineering at Indian Institute of Technology, Kanpur, India. In 1982 he moved to Indian Institute of Science, Bangalore, India. He is now the Chairman of the Centre for Atmospheric and Oceanic Sciences at Indian Institute of Science. He has done research in Atmospheric Sciences, Thermal Sciences and Solar Energy Utilization. He was a National Research Council Senior Resident Research Associate at NASA, Langley, Virginia from 1993 to 1995. He was one of the lead authors in the Intergovernmental Panel on Climate Change (IPPC) report on Climate Change in 1995. He was review editor of the IPCC report on Climate Change in 2001.

Ole John Nielsen, was born in Denmark in 1954. He received his M.Sc. in Chemistry and Physics in 1978 and his Ph.D. in Atmospheric Chemistry in 1984 from Copenhagen University under the supervision of Børge Bak. From 1978 to 1999 he worked at Risoe National Laboratory (Denmark), 5 years as head of the Section for Chemical Reactivity. In 1995 and 1996 he moved to Ford Research Center Aachen (Germany) where he worked as a manager of atmospheric science. In 1996 he received the Henry Ford Technology Award. In 1997 he was appointed adjunct professor in chemistry at Roskilde University. He is a member of the Danish Natural Science Research Council, the Head of Copenhagen Global Change Initiative (COGCI) network and Ph.D.-board, member of the Danish Academy (ATV), and the Danish member of the International Executive Committee for EUROTRAC. He has supervised numerous M.Sc. and Ph.D. students and has co-authored 145 scientific articles in the area of atmospheric science.

Ellie J. Highwood was born in France in 1972. She received her B.Sc. (Hons) in Physics ( $1^{\text {st }}$ class) from the University of Manchester in 1993 and her Ph.D. in Meteorology in 1997 from the University of Reading under the supervision of Prof. Brian Hoskins. She then spent 18 months as a research assistant in the same department working on the global warming impact of replacement gases for the chlorofluorocarbons and non-methane hydrocarbons. In 1998 she won a personal Postdoctoral Research Fellowship from the U.K. Natural Environment Research Council to study the climate response to 
ENVIRONMENTAL AND ECOLOGICAL CHEMISTRY - Vol. I - Greenhouse Gases and Global Warming - Timothy J. Wallington, Jayaraman Srinivasan, Ole John Nielsen, Ellie J. Highwood

changes in tropospheric aerosols. Since January 2001 she has been a lecturer in the Department of Meteorology at the University of Reading. Her research interests include the radiative and climatic impact of volcanic eruptions, Saharan dust storms and biomass burning. She has co-authored around 15 scientific articles in peer-reviewed publications. 